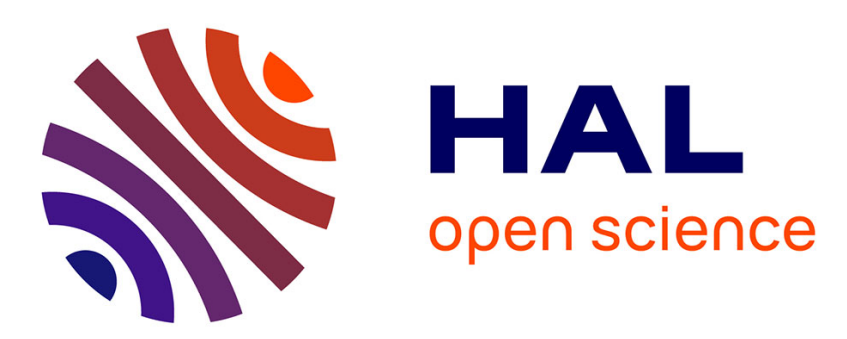

\title{
Deciphering the molecular mechanisms of anti-tubulin plant derived drugs
}

Pascale Barbier, Philipp O. Tsvetkov, Gilles Breuzard, François Devred

\section{To cite this version:}

Pascale Barbier, Philipp O. Tsvetkov, Gilles Breuzard, François Devred. Deciphering the molecular mechanisms of anti-tubulin plant derived drugs. Phytochemistry Reviews, 2014, 13 (1), pp.157-169. 10.1007/s11101-013-9302-8 . hal-01470519

\section{HAL Id: hal-01470519 https://hal-amu.archives-ouvertes.fr/hal-01470519}

Submitted on 24 Feb 2017

HAL is a multi-disciplinary open access archive for the deposit and dissemination of scientific research documents, whether they are published or not. The documents may come from teaching and research institutions in France or abroad, or from public or private research centers.
L'archive ouverte pluridisciplinaire HAL, est destinée au dépôt et à la diffusion de documents scientifiques de niveau recherche, publiés ou non, émanant des établissements d'enseignement et de recherche français ou étrangers, des laboratoires publics ou privés. 


\title{
Deciphering the molecular mechanisms of anti-tubulin plant derived drugs
}

\author{
P. Barbier $\cdot$ P. O. Tsvetkov $\cdot$ G. Breuzard • \\ F. Devred
}

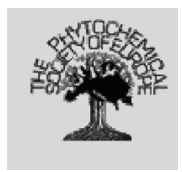

Received: 24 December 2012/ Accepted: 22 April 2013/Published online: 1 May 2013

(C) Springer Science+Business Media Dordrecht 2013

\begin{abstract}
Even though commercialized anticancer drugs are now produced by pharmaceutical companies, most of them were originally obtained from natural sources, and more particularly from plants. Indeed, many structurally diverse compounds isolated from plants or marine flora have been purified and synthesized for their anticancer bioactivity. Among these, several molecules belong to the class of anticancer drugs which target the microtubule cytoskeleton, either by stabilizing it or destabilizing it. To characterize the activity of these drugs and to understand in which physiological context they are more likely to be used as therapeutic agents, it is necessary to fully determine their interaction with tubulin. Understanding the molecular basis of their effects on microtubule cytoskeleton is an important step in designing analogs with greater pharmacological activity and with fewer side effects. In addition, knowing the molecular mechanism of action of each drug that is already used in chemotherapy protocols will also help to find strategies to circumvent resistance. By taking examples of known anti-tubulin plant derived drugs,
\end{abstract}

P. Barbier · G. Breuzard · F. Devred ( $\square)$

Aix-Marseille Université, Inserm, CRO2 UMR_S 911, Faculté de Pharmacie, 13385 Marseille, France

e-mail: francois.devred@univ-amu.fr

P. O. Tsvetkov

Engelhardt Institute of Molecular Biology, Russian

Academy of Sciences, Vavilov Street 32,

119991 Moscow, Russia we show how identification of microtubule targeting agents and further characterization of their activity can be achieved combining biophysical and biochemical approaches. We also illustrate how continuing in depth study of molecules with already known primary mechanisms of action can lead to the discovery of new targets or biomarkers which can open new perspectives in anticancer strategies.

Keywords Cancer - Microtubule $\cdot$ Microtubuletargeting agent $\cdot$ Plant-derived drugs $\cdot$ Molecular mechanism
Abbreviations
AUC Analytical ultracentrifugation
ITC Isothermal titration calorimetry
MAP Microtubule associated protein
MT Microtubule
MTA Microtubule targeting agent
SPR Surface plasmon resonance
VA Vinca alkaloid

\section{Introduction}

Humans have used plants as medicines for millennia. In anticancer chemotherapies, $14 \%$ of the molecules used are natural products and $23 \%$ correspond to modified natural molecules. The 
remaining $63 \%$ are synthetic compounds, but $15 \%$ have a natural pharmacophore (Butler and Newman 2008; Monneret 2010). Thus, nature is an important source of innovative products in oncology. Anticancer molecules, which act to block the cell division of tumor cells that have lost proliferation control, are usually classified according to their target. Microtubule targeting agents (MTAs) correspond to molecules that target the major constituent of the microtubules (MTs), tubulin. Microtubules are polarized cylinders of $25 \mathrm{~nm}$ of diameter constituted of 13 protofilaments of $\alpha \beta$-tubulin heterodimers. $\alpha$-tubulin is exposed to the more stable extremity, called (-)end, generally linked to the microtubule organizing center, while $\beta$-tubulin is exposed at the more dynamic extremity, called (+)end. Microtubules undergo dynamic instability (Mitchison and Kirschner 1984), which is characterized by transitions between self-assembly and depolymerization phases (catastrophes) and vice versa (rescues). Through their dynamicity, microtubules control cell shape and such processes as motility, mitosis, intracellular vesicle transport, organization, as well as positioning of membranous organelles (Desai and Mitchison 1997; Oakley 2000; Sharp et al. 2000). Microtubule dynamicity is regulated by GTP hydrolysis, post-translational modifications and by microtubule associated proteins (MAPs) that can either stabilize them (like tau) or destabilize them (like stathmin). Similarly to MAPs, MTAs also bind to free tubulin and/or microtubules to perturb microtubule dynamics and by consequence their function, leading to mitotic arrest and apoptosis. Even though many anti-tubulin plant derived MTAs were discovered a long time ago and have been used in chemotherapies since, their complete mechanism of action is often not yet elucidated. Understanding their molecular mechanism of action (binding site, consequence on tubulin polymerization and multiple targets) is important to understand their efficacy and to find ways to improve these agents. After presenting briefly the main anti-tubulin plant derived molecules, we will discuss the methodology to identify and characterize their binding to tubulin and their anti-microtubule activity. Finally, we will demonstrate how further study of molecules with well-characterized primary molecular mechanism can lead to the discovery of new targets and sometimes new anticancer strategies.

\section{Anti-tubulin plant derived molecules}

Microtubule targeting agents, which either stabilize or destabilize microtubules, can be classified structurally into three families according to their binding site on tubulin dimers (Fig. 1). The first family is that of paclitaxel isolated from Taxus brevifolia in the $90 \mathrm{~s}$. It binds on $\beta$-subunit (Nogales et al. 1995) in the lumen of microtubules (Matesanz et al. 2011) and stabilizes microtubules by straightening GDP-tubulin protofilaments into a conformation resembling GTP-tubulin (Buey et al. 2005). Interestingly, in addition to paclitaxel and its hemisynthetic analog docetaxel, other molecules with potential anti-cancer activity isolated from non plant organisms, can bind to this same site on tubulin. The second family is that of vinblastine and vincristine isolated from Catharanthus roseus in the middle of the last century. Vinblastine was studied for its potential antidiabetic properties before its anti-leukemia activity was discovered in 1957. Nowadays, this family bears many members, among which 6 are used in clinical oncology, the latest one being vinflunine (Jacquesy and Jouannetaud 2005; Kruczynski et al. 1998). Vinca alkaloids bind tubulin at the interdimeric interface of two heterodimers (Gigant et al. 2005) principally at the (+)end of the microtubules to destabilize them. In addition to vinblastine, vincristine and their hemisynthetic analog vinorelbine, other structurally different plant derived molecules bind to the vinca-alkaloid domain of tubulin, including Maytensin isolated from the shrub Maytenusovatus (Kupchan et al. 1972). A derivative of this molecule, DM1 conjugated to a monoclonal antibody against HER2 receptor is in phase III clinical trials for the breast cancer treatment (Teicher and Doroshow 2012). The third family is that of colchicine, isolated from colchicum autumnale in 1820 (Pelletier and Caventou 1820). Its antitumor activity was first described in 1935 (Amoroso 1935). It binds on the $\beta$-tubulin subunit at the intradimeric interface of the heterodimer (Ravelli et al. 2004) rendering it unable to form microtubules. However, since colchicine causes severe toxicity at the doses required for anticancer effects, it is used at much lower doses for other therapeutic purposes, such as therapy for gout (Doghramji 2011) and familial Mediterranean fever (Cabili et al. 1985). Nevertheless, numerous plant derived colchicine analogs are currently under investigation for their potential anti-cancer applications, 
Fig. 1 Three main antitubulin plant-derived drugs tubulin binding sites: (1) paclitaxel site located on $\beta$-tubulin in the lumen of MT; (2) vinblastine site located at the inter-dimeric interface of two heterodimers; (3) colchicine site located on the $\beta$-tubulin at the intra-subunit interface of one heterodimer

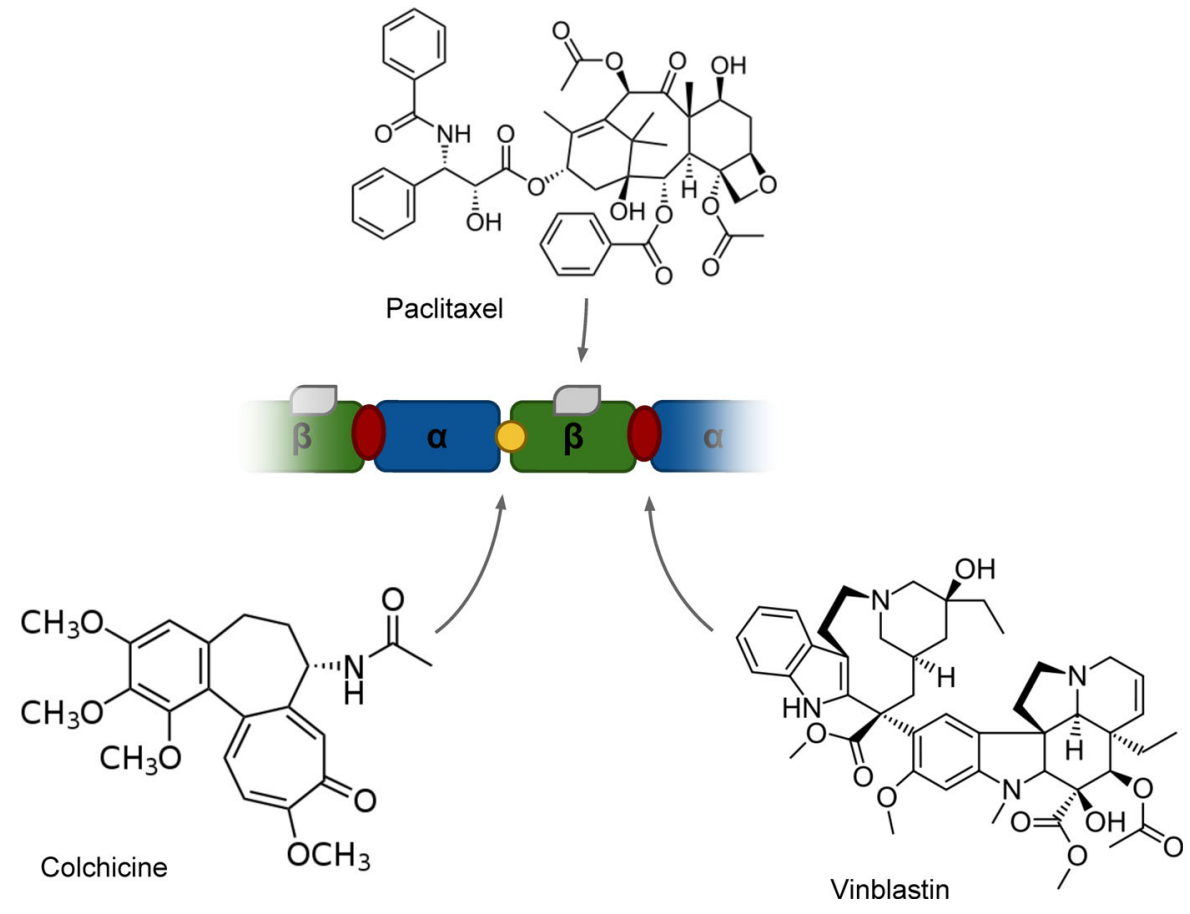

such as combretastatin A-4 (CA4), isolated first from Combretum caffrum, an Eastern Cape South African Bush Willow tree (Pettit et al. 1987) which is undergoing clinical and preclinical trials as a vascular-targeting drug. Others include Quercetin that is present in capparis spinosa (Gupta and Panda 2002), Steganacin extracted from Steganataenia araliacea Hochest (Kupchan et al. 1973), Salvinal from Salvia miltiorrhizae Bunge (Chang et al. 2004), and podophyllotoxin isolated from Callitrus drummondii (Kier et al. 1963), as well as Ottelione A and B extracted from the Indian plant Ottelia alismoides (Ayyad et al. 1998). Figure 2 shows the diversity of the structure that can be found within a family of analogs binding on the same site on tubulin (here colchicine).

Aside from these three well-defined pharmacological sites, some molecules derived from plants have been shown to bind elsewhere on tubulin. It was the case of Noscapine, a phthalideisoquinoline alkaloid constituting 1-10\% of the alkaloid content of opium (for review see Mahmoudian and Rahimi-Moghaddam 2009) and caulerpenyne isolated from Caulerpa Taxifolia (Pesando et al. 1996). There is a constant need of new molecules or new variants to counteract the potential drug resistance phenomenon. One cause of drug resistance to MTAs is the increase in drug transport activity of ATP-binding cassette (ABC) transporters (Gottesman et al. 1996; Kavallaris 2010). Another cause is the mutation or alteration in expression of certain isotypes of tubulin. Alteration of class III $\beta$-tubulin expression as well as amino acid substitution in the class I and III are also responsible for resistance to taxane and vinca alkaloids (Stengel et al. 2010). Finally, chemotherapeutic failure may also be due to the characteristics of the molecule itself. For instance, natural CA-4 isomerizes into an inactive form and suffers from low solubility. These observations, taken together with the success of the existing MTAs, significant efforts are being made on discovery, synthesis and clinical trial development of new derivatives. When a novel potential anti-tubulin molecule is characterized, its structure is usually compared with those of the three leading compounds, paclitaxel, vinblastine and colchicine. However, many examples have proven that molecules with different structures can bind to the same tubulin binding site and, reversely, many molecules with similar structures can bind on different biological targets. For example, Coumarins a group of plant-derived polyphenolic compounds, possess a wide variety of cytoprotective and modulatory functions: antioxidant, antiviral, antimicrobial and anticancer activity 
<smiles>COc1ccc2c(c1)C(NC(C)=O)CCc1cc(OC)c(OC)c(OC)c1-2</smiles><smiles>O=c1c(O)c(-c2ccc(O)c(O)c2)oc2cc(O)cc(O)c12</smiles><smiles>C=CC1CC(Cc2ccc(OC)c(O)c2)[C@H]2C(=O)C=CC(=C)[C@H]12</smiles>

Ottelione A<smiles>COc1cc(-c2oc3c(OC)cc(CCCO)cc3c2C=O)ccc1O</smiles>

Salvinal<smiles>COc1cc([C@H]2c3cc4c(cc3[C@@H](O)[C@@H]3COC(=O)[C@H]23)OCO4)cc(OC)c1OC</smiles>

Quercetine<smiles>COc1cc2c(c(OC)c1OC)-c1cc3c(cc1C(OC(C)=O)[C@H]1COC(=O)[C@@H]1C3)OCO2</smiles>

Stegamicin

Fig. 2 Plant-derived anti-tubulin molecules which bind to tubulin on the colchicine binding site

(Kontogiorgis et al. 2012). For all these reasons, evaluating the anti-tubulin potential of a new molecule is necessary, and should be done both on cellular and molecular levels (Fig. 3). In the following sections, we discuss the experimental strategies and methods that can be used to identify and characterize the anti-tubulin activity of a compound.

\section{Impact of potential drugs on microtubule network}

The first step for the study of new molecule or plant extract with a suspected antitubulin effect is to evaluate its cytotoxicity on various cancer cell lines. Indeed, most anti-tubulin agents interfering with microtubule formation cause mitotic arrest. This mitotic arrest and subsequent apoptosis can be easily monitored through typical profiles in flow cytometry (Fig. 4a). Apoptosis is then confirmed by the presence of several markers, such as phosphatidylserine on the extracellular surface of plasma membrane, caspase activation in the intracellular compartment, or mitochondrial membrane potential collapse (Niu and Chen 2010; Tait and Green 2010). Nevertheless, antitubulin drugs are not the only molecules inducing these processes. Inhibition of any of the other actors of the cell cycle, such as cell cycle regulating kinases, motors proteins, or multiprotein complexes like APC/ C-Cdc20 complex or ubiquitin-proteasome system (Chan 2012), will have the same effect. For all of these reasons, it is necessary to observe the cellular microtubule network directly in cells to see if it is perturbed. This can be performed by labeling tubulin, either in live cells by transfection of fusion proteins labeled with fluorophore or on fixed cells using indirect immunofluorescence. Modifications of cellular microtubule network by the three leading compounds, paclitaxel, vinblastine and colchicine are now 


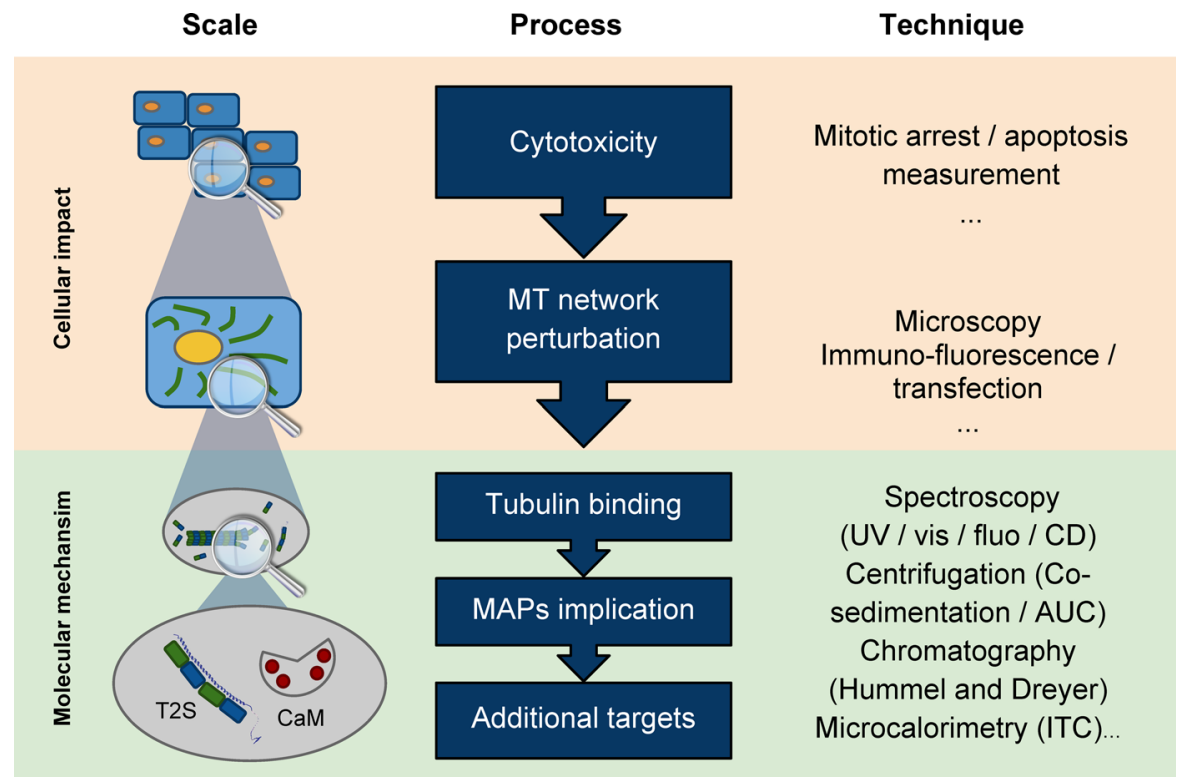

Fig. 3 General schema of drug candidates investigation to demonstrate their anti-tubulin activity and decipher their molecular mechanisms of action

well-known. Paclitaxel increases polymer mass, induces the formation of microtubule bundles in interphase cells (Fig. 4b) and leads to formation of pseudo asters during mitosis (Rowinsky et al. 1994). Colchicines and Vinblastine have the opposite effect on microtubule network, since they depolymerize microtubules. In the case of vinblastine, high concentrations (micromolar) lead to the formation of large tubulin polymers called "paracristals" (Takanari et al. 1990). At lower concentrations, where no macroscopic effect can be seen on microtubule network, these drugs are known to have an effect on microtubule dynamics which can be monitored by time-lapse video microscopy. Following the ends of individual microtubules at the cell periphery (Fig. 4c) enables one to obtain a great number of dynamicity parameters that characterize subtle effects of drugs, such as speed of growth, depolymerization, time spent in pause, frequency of transition from growth to depolymerization (catastrophe) or the opposite (rescue) (Gardner et al. 2012; Kirschner and Mitchison 1986; van der Vaart et al. 2009). This approach lead to the discovery that, although having opposite effect on the microtubule formation at high concentrations (stabilization or destabilization), the three leading compounds, paclitaxel, vinblastine and colchicine and their analogs usually perturb MT functions by decreasing microtubules dynamics instability (Jordan and Wilson 1998). Careful study of MT dynamicity allowed the discovery that treatment with very low concentrations of either paclitaxel or vinca alkaloids causes an increase in MT dynamicity in endothelial cells (Pasquier et al. 2007; Pourroy et al. 2006).

\section{Interaction of the MTA with tubulin}

Influence of MTAs on tubulin self-assembly

Showing that a cytotoxic molecule modifies both the cellular cycle and the microtubule network or induces apoptosis does not guarantee that the molecule itself is directly responsible of its effect on tubulin selfassembly. For example, taccalonolides isolated from the plant Tacca chantrieri, stabilize microtubules through a mechanism of action that does not involve direct tubulin binding, as shown by the fact that they were unable to bind to purified tubulin and to microtubules (Risinger and Mooberry 2010). It is thus necessary to verify if anti-tubulin activity of a molecule is due to direct tubulin binding in solution. Tubulin purified from brains is able to form microtubules in polymerization buffer (Lee and Timasheff 1975). The minimal tubulin concentration necessary to induce MT 

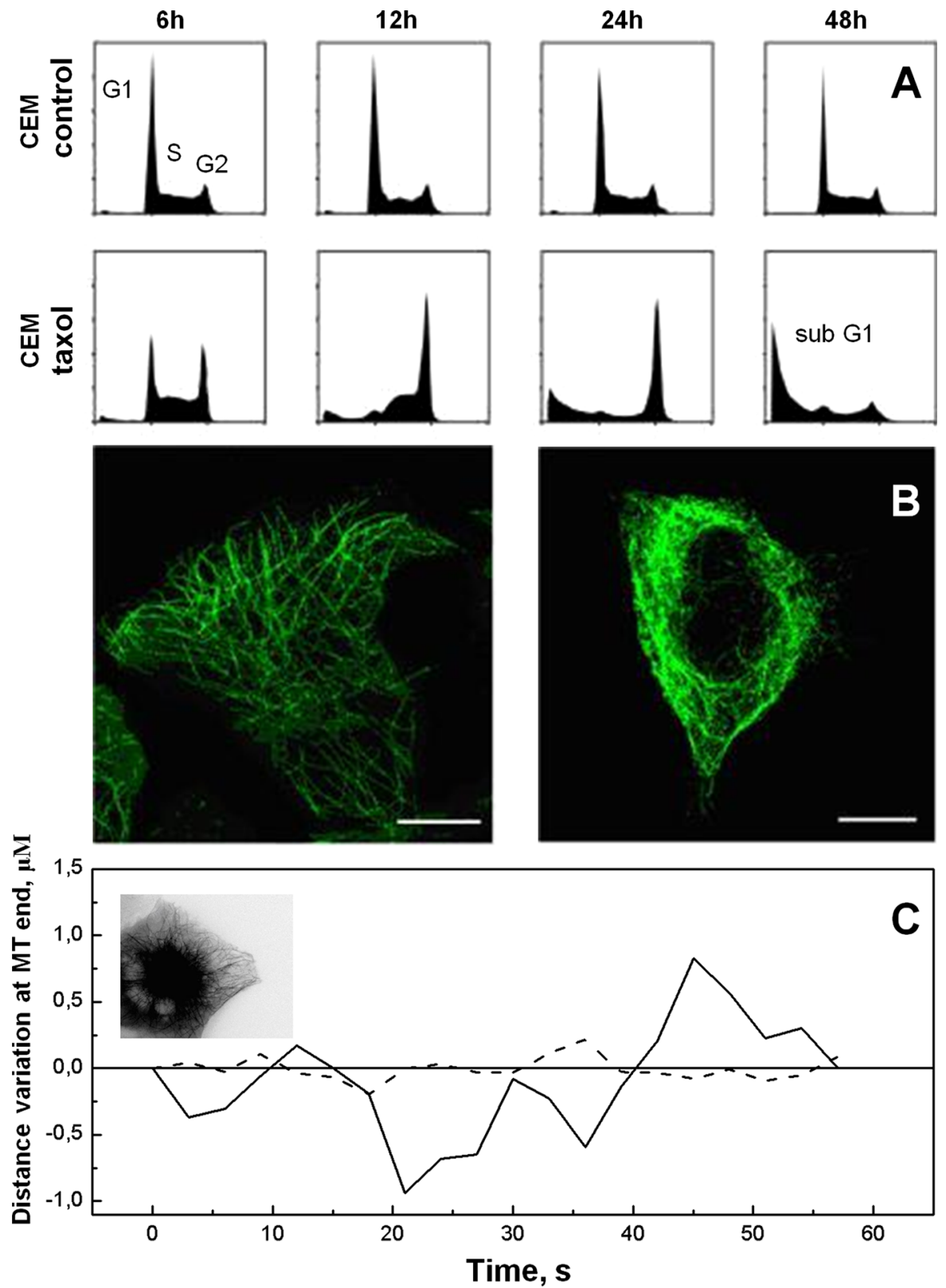

Fig. 4 a Cell cycle distribution determined by flow cytometry in CEM cells untreated (upper) or treated with antimicrotubule agent (lower) for 6, 12, 24 and $48 \mathrm{~h}$. The number of cells in the different cell cycle G1, S, G2 was analyzed by quantifying the DNA content using Propidium Iodure. This typical experiment shows an increase of cells in G2 and an appearance of cell population in subG1 indicating apoptosis and/or cell death as the drug incubation time increases. b Indirect immunofluorescence of microtubule cytoskeleton untreated (left) or treated with 10

formation is called critical tubulin concentration $(\mathrm{Cr})$. All the tubulin molecules above the $\mathrm{Cr}$ are going to self-assemble into microtubules. The amount of
$\mathrm{nM}$ of stabilizing agent during $4 \mathrm{~h}$. The well defined microtubule network switches to bundles in the cell periphery. The bars represent $10 \mu \mathrm{m}$. c Microtubule dynamic: The inset shows the microtubule network revealed by labeled tubulin expression by time laps video microscopy. The positions of the plus ends of individual microtubules, recorded using Metamorph software, were plotted versus time. The figure represents the evolution over time of two representative microtubule ends, a stable one (dashed line) and a more dynamic one (plane line)

tubulin polymerized into microtubules can be monitored by turbidimetry, i.e. absorbance at $350 \mathrm{~nm}$ (Fig. 5a). At this wavelength, the absorbance is 


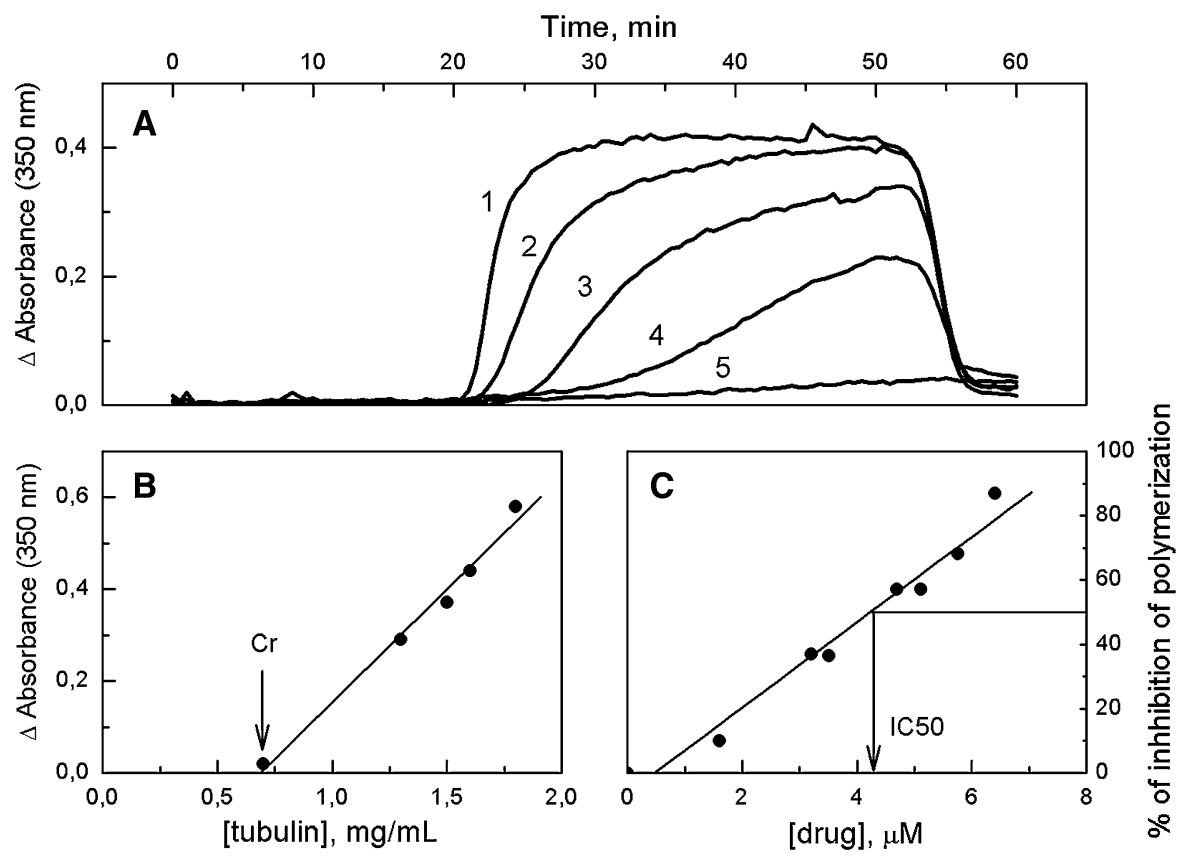

Fig. 5 Polymerization of tubulin into microtubules monitored by turbidimetry $(\mathrm{A} 350 \mathrm{~nm})$. a Typical time course variation of turbidimetry with either decreasing tubulin concentration or increasing inhibitor concentration (from 1 to 5 could). b In the first case, critical tubulin concentration $(\mathrm{Cr})$ for the formation of microtubule can be determined from the $\mathrm{x}$-intercept of the plot of the amount of microtubule (absorbance at $350 \mathrm{~nm}$ ) at the plateau in function of tubulin concentration. In this experiment, the $\mathrm{Cr}$ is $0.7 \mathrm{mg} / \mathrm{mL}$ (Devred et al. 2002) and can be reduced in presence of stabilizing agent or increased in presence of destabilizing agent. $\mathbf{c}$ In the second case, the concentration of drug necessary to inhibit the formation of microtubules by $50 \%$ (IC50) can be determined from the plot of the percentage of inhibition of microtubule formation in function of drug concentrations proportional to the amount of microtubules (Gaskin et al. 1975). The amount of tubulin polymerized in MT can also be monitored using DAPI fluorescence or sedimentation. Indeed, DAPI fluorescence enhancement upon its binding to microtubule is directly proportional to the concentration of polymerized tubulin (Bonne et al. 1985; Heusele and Bonne 1985). Sedimentation analysis is performed by centrifuging $(100,000 \mathrm{~g}$ during $15 \mathrm{~min})$ a solution of tubulin incubated at $37{ }^{\circ} \mathrm{C}$ in polymerization buffer. After centrifugation, a pellet containing microtubules and a supernatant containing unpolymerized tubulin are separated and can be quantified by various techniques (Spectroscopy UV-Visible, SDS-PAGE, HPLC). Plotting the amount of polymerized tubulin as function of tubulin concentration gives a linear relation, in which $\mathrm{x}$-intercept corresponds to the $\mathrm{Cr}$ (Fig. 5b). In presence of anti-tubulin molecules, $\mathrm{Cr}$ will decrease in the case of a stabilizer and increase in the case of destabilizers. In addition, in the case of a destabilizing agent, the speed of growth and/or the amount of MT will be reduced and the activity of the destabilizer can be quantified by its IC50, i.e. the drug concentration necessary for a $50 \%$ reduction in the amount of tubulin polymerized into microtubules (Fig. 5c).

Thermodynamic characterization of MTA-tubulin binding

Once a molecule has been shown to be a MTA, i.e. that it binds directly to tubulin and has a functional effect on microtubule stability, it becomes important to characterize the tubulin-MTA from a thermodynamic point of view. Indeed, knowledge of stoichiometry, binding constant as well as enthalpy and entropy variations will not only characterize the strength of the interaction, but also provide insights into the nature of the binding regions and driving forces of the interaction. To determine the thermodynamic parameters of tubulin-MTA interaction, a wide variety of techniques 
are available. Some of them rely on the direct determination of bound and free tubulin and/or MTA. Other methods, often referred as indirect, rely on the measurement of a signal proportional to the complex formed. In this last case, fitting the signal corresponding to the plot of the complex formation as a function of free ligand concentration will allow the determination of the stoichiometry $(\mathrm{N})$ and the association constant $(\mathrm{Ka})$. Over the past twenty years, MTA-tubulin interaction has thus been studied using a wide range of techniques, from biophysics to proteomics, depending on the nature and properties of the MTA : Hummel-Dreyer column gel permeation technique (Leynadier et al. 1993; Cruz-Monserrate et al. 2003), co-sedimentation (Smith and Jordan 2010), analytical ultracentrifugation (Alday and Correia 2009; Correia 2010; Lobert et al. 2007), differential UV-Visible spectroscopy (Barbier et al. 2010), circular dichroism (Peyrot et al. 1999), fluorescence (Bhattacharyya et al. 2010), nuclear magnetic resonance (Clement et al. 2010), isothermal titration microcalorimetry (Devred et al. 2010) as well as mass spectrometry (Calligaris et al. 2010). Tubulin's natural tendency to self-assemble makes some methods, such as SPR, difficult to use for studying MTA-tubulin interactions, whereas other methods, such as analytical ultracentrifugation, take advantage of this peculiarity. Analytical ultracentrifugation is a powerful method for the study of biomacromolecules behavior in solution. Three optical systems may be available (absorbance, interference, and fluorescence) to permit precise and selective observation of sedimentation in real time. In sedimentation velocity (SV) experiments, the movement of solutes in high centrifugal fields is a function of their sedimentation coefficients which are defined by their sizes, shapes, and eventual molecular interactions. In presence of vinca alkaloids, tubulin will self assemble into polymers, such as spirals and rings, which can then be quantified by analytical ultracentrifugation (Alday and Correia 2009; Lobert et al. 2007; Na and Timasheff 1980). Analyzing the increase of the sedimentation coefficient $\mathrm{S}$ measured as a function of increasing vinca alkaloid concentration (Lobert et al. 2007) allows one to determine both the affinity constant of the vinca alkaloid on tubulin and the constant of tubulin-tubulin interaction. Moreover, in the absence of tubulin self-assembly, one can also determine the drug binding to tubulin. In this case, the molecule (ligand, drug) must absorb at a wavelength different from that absorbed by tubulin (in the visible range for instance) and preferably be too small to sediment. When ligand wavelength is used for detection, the signal is proportional to the tubulin bound ligand concentration and the baseline determination determines the free ligand concentration. As for other direct methods, such as Hummel and Dreyer, the affinity constant could be obtained from a Scatchard plot or from a direct fit with saturation equation. One useful indirect method to study drug-tubulin interaction is isothermal titration calorimetry, since it can be used to access all the thermodynamic parameters of the interaction. The principle of isothermal titration calorimetry (ITC) is based on the heat exchange which occurs when molecules interact. By measuring the heat which is emitted or absorbed during consecutive injections of drug into protein solution, the calorimeter plots isotherm of binding can be obtained after a single one-hour experiment. Fitting experimental data with theoretical model enables one to determine all thermodynamic parameters of interaction: stoichiometry $(N)$, association constant $\left(K_{a}\right)$, enthalpy of binding $(\Delta H)$ and calculate free Gibbs energy $(\Delta G)$ and entropy of binding $(\Delta S)$. For all interactions $\Delta G$ is always negative. The signs of enthalpy and entropy represent the energetic signature of the interaction. If $\Delta H$ is negative (enthalpy favorable reaction), the entropic component of reaction could be either favorable $(\Delta S>0)$ or unfavorable $(\Delta S<0)$, as long as $\Delta G$ stays negative. In case of positive $\Delta H$, the entropy of binding should be favorable $(\Delta S>0)$ to keep variation of Gibbs energy negative. The energetic signature of the interaction depends on the nature of the driving forces of the interaction (O'Brien and Haq 2004). Indeed, in case of positive $\Delta H$, reaction is usually driven by hydrophobic interactions, while negative $\Delta H$ and $\Delta S$ indicate the formation of hydrogen bonds or van der Waals interactions upon binding. Comparison of energetic signature of the interaction for two similar drugs could provide chemists with very useful information for rational drug design. ITC has been used to investigate tubulin interaction with a number of drugs, including vinca alcaloids. Recently it was used to demonstrate that stathmin dramatically increases the affinity of vinblastin to tubulin (Fig. 6) and vice versa (Devred et al. 2008). Like AUC, ITC measurements are performed in solution without immobilization or modification of investigated molecules in near physiological 


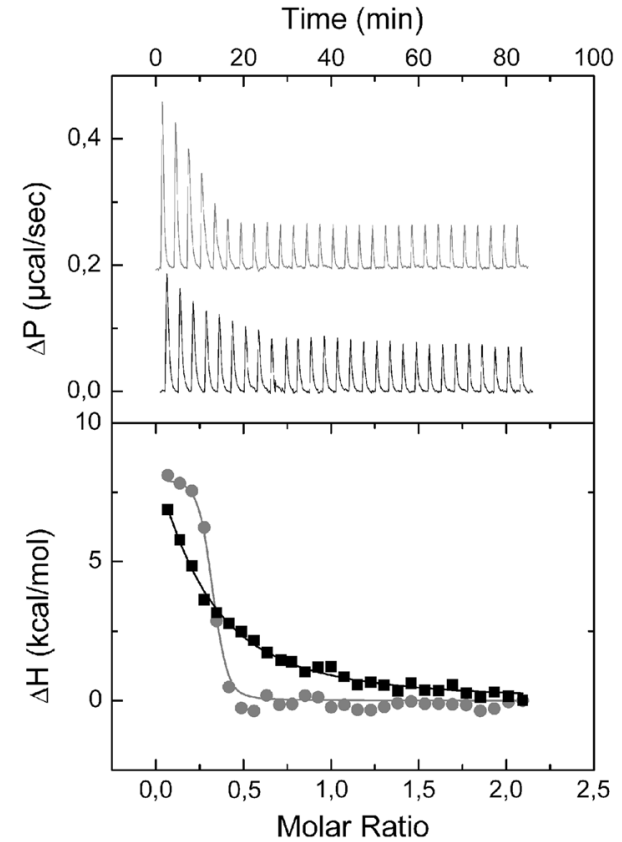

Fig. 6 Interaction of Vinblastine (VLB) to tubulin monitored by isothermal titration calorimetry (ITC). Top panel Titration of tubulin by VLB (top panel); bottom panel binding isotherms and best fit using model of one-set-of-sites. Tubulin is titrated by vinblastine at $10^{\circ} \mathrm{C}$ in $20 \mathrm{mM} \mathrm{NaPi}$ buffer in the presence of $0.1 \mathrm{mM}$ GTP, $\mathrm{pH} 6.5$, in the absence (black curve) and in the presence (gray curve) of stathmin. Parameters obtained are $\Delta \mathrm{H}=16 \mathrm{kcal} \mathrm{mol}^{-1} ; \Delta \mathrm{S}=83 \mathrm{cal} \mathrm{mol}^{-1} \mathrm{~K}^{-1} ; \mathrm{K}_{\mathrm{a}}=5 \times 10^{5}$ in the absence of stathmin and $\Delta \mathrm{H}=8 \mathrm{kcal} \mathrm{mol}^{-1}$; $\Delta \mathrm{S}=63 \mathrm{cal} \mathrm{mol}^{-1} \mathrm{~K}^{-1} ; \mathrm{K}_{\mathrm{a}}=2.5 \times 10^{7}$ in the presence of stathmin evidencing a 50 fold increase in the affinity of vinblastine for tubulin in the presence of stathmin

conditions. In addition, ITC does not depend on solution transparency as spectroscopic methods do, nor on ligand's size as SPR does. All this makes ITC the method of choice to study interactions of drugs with their targets for $\mathrm{K}_{\mathrm{a}}$ ranging from $10^{-3}$ to $10^{-8} \mathrm{M}^{-1}$. Particular care should be taken when choosing the model that will be used to fit the experimental data, always keeping in mind that the fact that data fit a model does not necessarily mean that the reaction is not more complex. This is why it is always necessary to confirm the parameters obtained by one technique by other methods.

\section{MTAs' additional mechanisms of action}

Vinca alkaloids are a good example of drugs that have been used in chemotherapies for a long time but are still under intensive study. Even though their interaction with tubulin has been characterized, additional studies have revealed new mechanisms of action, such as their interplay with MAPs or their interaction with calmodulin. Since crystallographic data showed that vinca alkaloids and stathmin could bind simultaneously on the same tubulin dimers (Gigant et al. 2005), and since cellular data demonstrated that stathmin could modify the antimitotic efficiency of vinca alkaloids (Alli et al. 2007; Iancu et al. 2001), functional interplay between stathmin and vinca alkaloids was investigated at the molecular level (Devred et al. 2008). AUC and ITC, revealed significant increase of the binding constant of vinblastine for tubulin in presence of stathmin and vice versa, thus revealing a novel mechanism of action of vinca alkaloids. This family of drugs acts not only directly on MT by binding at the interface between successive tubulin dimers which tends to depolymerize MTs, but also indirectly by increasing the activity of stathmin. Since stathmin expression and/or activity has been shown to be upregulated in human cancer (Belletti and Baldassarre 2011), this newly discovered mechanism of action highlights stathmin as an important mediator of cell sensitivity to vinblastine, and even a potential target for cancer therapeutics. In addition, vinca alkaloids have been shown to have secondary targets which can influence MT network regulation. Indeed, several vinca alkaloids bind to the universal calcium signal transductor-calmodulin (Vertessy et al. 1998). Based on structural studies, it was originally hypothesized that this binding could inhibit interaction of $\mathrm{CaM}$ with its other targets. Some $\mathrm{CaM}$ targets are directly implicated in MT regulation, such as MAP6, also known as STOP (for stable-tubulin-only-polypeptide), which stabilizes microtubule in a calciumdependent manner (Pirollet et al. 1992a, b). This CaMmediated mechanism of vinca alkaloids action could explain the differences in efficacy of different vinca family members that have otherwise similar binding constants with tubulin. For example, vinflunine, the newest member of the vinca alkaloid family, displays a better activity than vinblastine against a number of murine tumors and human tumor xenografts (Kruczynski and Hill 2001). It also arrests mitosis in cancer cells without significant toxic side effects (Bennouna et al. 2005). Nevertheless, vinflunine binds to tubulin with an overall affinity several-fold lower than vinblastine or vincrisitine. Vinflunine turned out to be a better inhibitor of STOP binding to CaM, 
Fig. 7 Microtubule depolymerizing mechanisms of action of Vinca alkaloid: (1) direct anti-tubulin action leads to depolymerization of microtubules in favor of curved protofilaments (2) indirect action by increasing stathmin activity (3) indirect action by binding to $\mathrm{CaM}$ which releases other MAPs such as MAP6

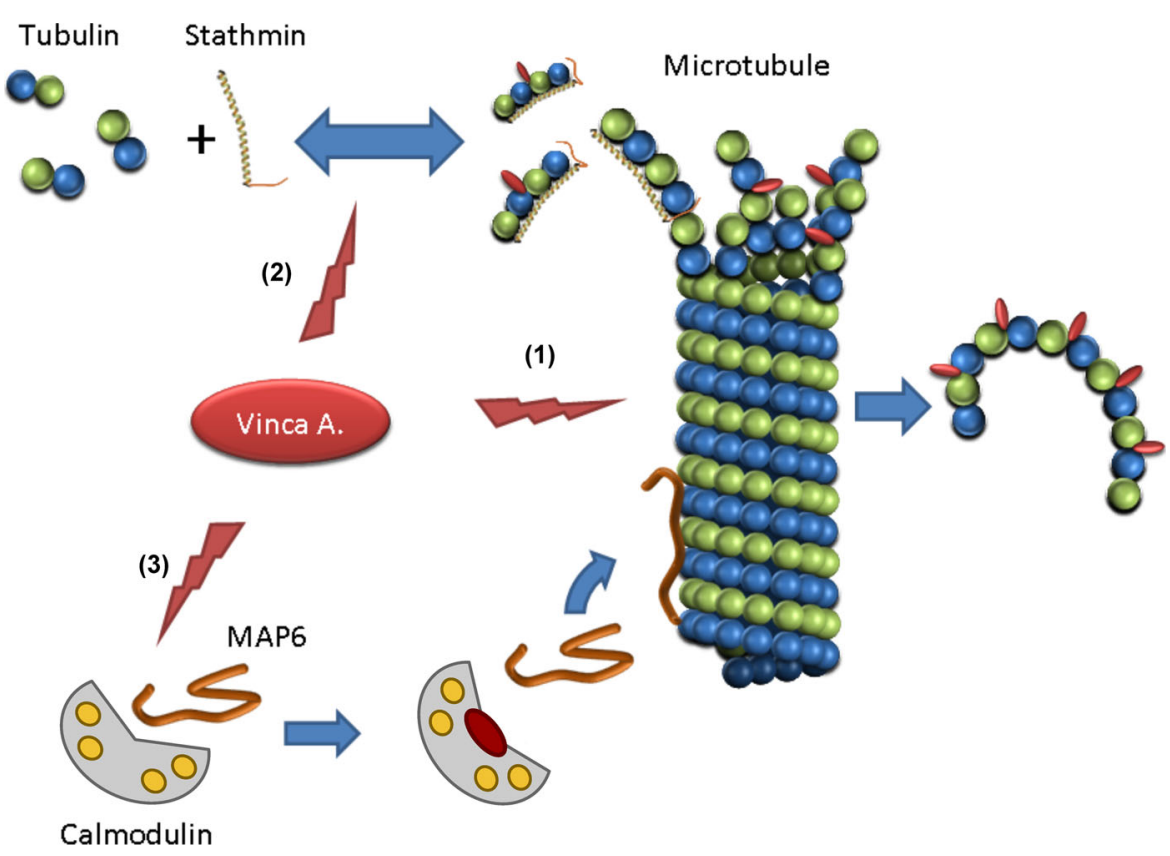

suggesting that vinflunine's superior antitumor efficacy and lower toxicity in vivo could be mediated by its interaction with CaM (Makarov et al. 2007). Recent study on another member of vinca alkaloid family, vinorelbine, supports the hypothesis about importance of impact of "secondary" targets in overall action of vinca alkaloids (Tsvetkov et al. 2011). ITC showed that vinorelbine binding sites on CaM are different from other vinca alkaloids family members including vinblastine. This could explain why, despite very similar binding parameters on tubulin, vinorelbine and vinblastine (Lobert et al. 2007) found such a different use in clinics. This study confirms the hypothesis that vinca alkaloids induced effects are not confined to direct binding to tubulin and that other targets, such as $\mathrm{CaM}$, can modulate vinca alkaloid toxicity and therapeutic effects. Both of these examples show that vinca alkaloids, which have originally been defined as tubulin interacting drugs, may have "secondary" effects or even targets (summarized in Fig. 7), which in some situation might have greater impact on cell function than the "primary" effect on tubulin. Therefore, understanding of these indirect effects of vinca alkaloids is important not only for development of novel antitumor drugs, but also for possible corrections of existing therapeutic schemes by taking into account the expression of target proteins. Considering the number of signaling pathways in which CaM plays a role, phenotype of tumors that are going to be treated with vinca alkaloids should be monitored carefully.

\section{Conclusion}

Plants are still one of the greatest sources of anti-cancer molecules. A number of methods are currently used to decipher the molecular mechanisms of plant-derived molecules, which is crucial for anti-cancer therapies. First, binding assays allow one to confirm that the target is indeed tubulin rather than some intermediate cofactors. Second, thermodynamic characterization of the interaction allows the quantitative structure-activity relationship studies necessary to choose between several semisynthetic variants of a natural molecule. Finally, studies at the molecular level may lead to the discovery of new modulators responsible for the fine tuning that will in term be used to explain small variability in the therapeutic response. A better knowledge of MTAtubulin mechanisms will not only lead to a better understanding of the resistance to anticancer drugs, but also to the discovery of new biomarkers of even new targets, to develop new anti-cancer strategies from sometimes very old natural molecules.

Acknowledgments This work was supported by Molecular and Cellular Biology Program of the Russian Academy of 
Sciences. We thank Dr. Svetlana Gorkhova for helpfull discussion and Roqiya Nouar for help with illustrations.

\section{References}

Alday PH, Correia JJ (2009) Macromolecular interaction of halichondrin B analogues eribulin (E7389) and ER-076349 with tubulin by analytical ultracentrifugation. Biochemistry 48:7927-7938

Ayyad SE, Judd AS, Shier WT, Hoye TR (1998) Ottelinones A and B: potently cytotoxic 4-methylene-2-cyclohexones from Ottelia alismoides. J Org Chem 63:8102-8106

Alli E, Yang JM, Ford JM, Hait WN (2007) Reversal of stathmin-mediated resistance to paclitaxel and vinblastine in human breast carcinoma cells. Mol Pharmacol $71: 1233-1240$

Amoroso EC (1935) Colchicine and tumor growth. Nature 135:266

Barbier P, Dorleans A, Devred F, Sanz L, Allegro D, Alfonso C, Knossow M, Peyrot V, Andreu JM (2010) Stathmin and interfacial microtubule inhibitors recognize a naturally curved conformation of tubulin dimers. J Biol Chem 285:31672-31681

Belletti B, Baldassarre G (2011) Stathmin: a protein with many tasks. New biomarker and potential target in cancer. Expert Opin Ther Targets 15:1249-1266

Bennouna J, Campone M, Delord JP, Pinel MC (2005) Vinflunine: a novel antitubulin agent in solid malignancies. Expert Opin Investig Drugs 14(10):1259-1267

Bhattacharyya B, Kapoor S, Panda D (2010) Fluorescence spectroscopic methods to analyze drug-tubulin interactions. Methods Cell Biol 95:301-329

Bonne D, Heusele C, Simon C, Pantaloni D (1985) 4',6-Diamidino-2-phenylindole, a fluorescent probe for tubulin and microtubules. J Biol Chem 260:2819-2825

Buey RM, Barasoain I, Jackson E, Meyer A, Giannakakou P, Paterson I, Mooberry S, Andreu JM, Diaz JF (2005) Microtubule interactions with chemically diverse stabilizing agents: thermodynamics of binding to the paclitaxel site predicts cytotoxicity. Chem Biol 12:1269-1279

Butler MS, Newman DJ (2008) Mother nature's gifts to diseases of man: the impact of natural products on anti-infective, anticholestemics and anticancer drug discovery. Prog Drug Res 65(1):3-44

Cabili S, Zemer D, Pras M, Aviram A, Sohar E, Gafni J (1985) The prevention of amyloidosis in familial mediterranean fever with colchicine. Proc Eur Dial Transpl Assoc Eur Ren Assoc 21:709-711

Calligaris D, Verdier-Pinard P, Devred F, Villard C, Braguer D, Lafitte D (2010) Microtubule targeting agents: from biophysics to proteomics. Cell Mol Life Sci 67(7):1089-1104

Chan KS, Koh CG, Li HY (2012) Mitosis-targeted anti-cancer therapies: where they stand. Cell Death Disease 3:e411. doi:10.1038/cddis.2012.148

Chang JY, Chang CY, Kuo CC, Chen LT, Wein YS, Kuo YH (2004) Salvinal, a novel microtubule inhibitor isolated from Salvia miltiorrhizae Bunge (Danshen), with antimitotic activity in multidrug-sensitive and -resistant human tumor cells. Mol Pharmacol 65(1):77-84
Clement MJ, Savarin P, Adjadj E, Sobel A, Toma F, Curmi PA (2010) Probing interactions of tubulin with small molecules, peptides, and protein fragments by solution nuclear magnetic resonance. Methods Cell Biol 95: 407-447

Correia JJ (2010) Analysis of tubulin oligomers by analytical ultracentrifugation. Microtubules in Vitro 95:275-288

Cruz-Monserrate Z, Mullaney JT, Harran PG, Pettit GR, Hamel E (2003) Dolastatin 15 binds in the vinca domain of tubulin as demonstrated by Hummel-Dreyer chromatography. Eur J Biochem 270:3822-3828

Desai A, Mitchison TJ (1997) Microtubule polymerization dynamics. Annu Rev Cell Dev Biol 13:83-117

Devred F, Barbier P, Lafitte D, Landrieu I, Lippens G, Peyrot V (2010) Microtubule and MAPs: thermodynamics of complex formation by AUC, ITC, fluorescence, and NMR. Methods Cell Biol 95:449-480

Devred F, Douillard S, Briand C, Peyrot V (2002) First tau repeat domain binding to growing and taxol-stabilized microtubules, and serine 262 residue phosphorylation. FEBS Lett 523:247-251

Devred F, Tsvetkov PO, Barbier P, Allegro D, Horwitz SB, Makarov AA, Peyrot V (2008) Stathmin/Op18 is a novel mediator of vinblastine activity. FEBS Lett 582: 2484-2488

Doghramji PP (2011) Managing your patient with gout: a review of treatment options. Postgrad Med 123:56-71

Gardner MK, Zanic M, Howard J (2012) Microtubule catastrophe and rescue. Curr Opin Cell Biol

Gaskin F, Cantor CR, Shelanski ML (1975) Biochemical studies on the in vitro assembly and disassembly of microtubules. Ann N Y Acad Sci 253:133-146

Gigant B, Wang C, Ravelli RB, Roussi F, Steinmetz MO, Curmi PA, Sobel A, Knossow M (2005) Structural basis for the regulation of tubulin by vinblastine. Nature 435 : 519-522

Gottesman MM, Pastan I, Ambudkar SV (1996) P-glycoprotein and multidrug resistance. Curr Opin Genet Dev 6:610-617

Gupta K, Panda D (2002) Perturbation of microtubule polymerization by quercetin through tubulin binding: a novel mechanism of its antiproliferative activity. Biochemistry 41:13029-13038

Heusele C, Bonne D (1985) Role of DAPI in microtubule reactions at steady-state. Biochem Biophys Res Commun 133:662-669

Iancu C, Mistry SJ, Arkin S, Wallenstein S, Atweh GF (2001) Effects of stathmin inhibition on the mitotic spindle. J Cell Sci 114:909-916

Jacquesy JC, Jouannetaud MP (2005) Vinflunine: a new anticancer fluorinated agent derived from Vinca-alkaloids. Ann Pharm Fr 63:28-34

Jordan MA, Wilson L (1998) Use of drugs to study role of microtubule assembly dynamics in living cells. Methods Enzymol 298:252-276

Kavallaris M (2010) Microtubules and resistance to tubulinbinding agents. Nat Rev Cancer 10:194-204

Kirschner MW, Mitchison T (1986) Microtubule dynamics. Nature 324:621

Kier LB, Fitzgerald DB, Burgett S (1963) Isolation of podophyllotoxin from Callitrus drummondii. J Pharm Sci 52:502-503 
Kontogiorgis C, Detsi A, Hadjipavlou-Litina D (2012) Coumarin-based drugs: a patent review (2008-present). Expert Opin Ther Pat 22:437-454

Kruczynski A, Colpaert F, Tarayre JP, Mouillard P, Fahy J, Hill BT (1998) Preclinical in vivo antitumor activity of vinflunine, a novel fluorinated Vinca alkaloid. Cancer Chemother Pharmacol 41:437-447

Kruczynski A, Hill BT (2001) Vinflunine, the latest Vinca alkaloid in clinical development. A review of its preclinical anticancer properties. Crit Rev Oncol Hematol 40:159-173

Kupchan SM, Komoda Y, Court WA et al (1972) Maytansine, a novel antileukemic ansa macrolide from Maytenus ovatus. J Am Chem Soc 94:1354-1356

Kupchan SM, Britton RW, Ziegler MF, Gilmore CJ, Restivo RJ, Bryan RF (1973) Steganacin and Steganangin, novel Antileukemic Lignan Lactones from Steganataenia ara/ iacea. J Am Chem Soc 95:1335-1336

Lee JC, Timasheff SN (1975) The reconstitution of microtubules from purified calf brain tubulin. Biochemistry 14:5183-5187

Leynadier D, Peyrot V, Sarrazin M, Briand C, Andreu JM, Rener GA, Temple C (1993) Tubulin Binding of 2 1-Deaza-7,8-Dihydropteridines with Different Biological Properties-Enantiomers Nsc 613862 (S)-(-) and Nsc $613863(\mathrm{R})-(+)$. Biochemistry 32:10675-10682

Lobert S, Ingram JW, Correia JJ (2007) The thermodynamics of vinca alkaloid-induced tubulin spirals formation. Biophys Chem 126:50-58

Mahmoudian M, Rahimi-Moghaddam P (2009) The anti-cancer activity of noscapine: a review. Recent Pat Anti-Cancer Drug Discovery 4:92-97

Makarov AA, Tsvetkov PO, Villard C, Esquieu D, Pourroy B, Fahy J, Braguer D, Peyrot V, Lafitte D (2007) Vinflunine, a novel microtubule inhibitor, suppresses calmodulin interaction with the microtubule-associated protein STOP. Biochemistry 46:14899-14906

Matesanz R, Rodriguez-Salarichs J, Pera B, Canales A, Andreu JM, Jimenez-Barbero J, Bras W, Nogales A, Fang WS, Diaz JF (2011) Modulation of microtubule interprotofilament interactions by modified taxanes. Biophys J 101:2970-2980

Mitchison T, Kirschner M (1984) Dynamic instability of microtubule growth. Nature 312:237-242

Monneret C (2010) Current impact of natural products in the discovery of anticancer drugs. Ann Pharm Fr 68:218-232

Na GC, Timasheff SN (1980) Thermodynamic linkage between tubulin self-association and the binding of vinblastine. Biochemistry 19:1355-1365

Niu G, Chen X (2010) Apoptosis imaging: beyond annexin V. J Nucl Med 51:1659-1662

Nogales E, Wolf SG, Khan IA, Luduena RF, Downing KH (1995) Structure of tubulin at 6.5 A and location of the taxol-binding site. Nature 375:424-427

Oakley BR (2000) An abundance of tubulins. Trends Cell Biol 10:537-542

O'Brien R, Haq I (2004) Applications of biocalorimetry : binding, stability and enzyme kinetics. In: Ladbury JE, Doyle ML (eds) Biocalorimetry 2: applications of calorimetry in the biological sciences. Wiley, Chichester
Pasquier E, Andre N, Braguer D (2007) Targeting microtubules to inhibit angiogenesis and disrupt tumour vasculature: implications for cancer treatment. Curr Cancer Drug Targets 7:566-581

Pelletier JP, Caventou J (1820). J Ann Chim Phys 1469

Pesando D, Lemée R, Ferrua C, Amade P, Girard JP (1996) Effects of caulerpenyne, the major toxin from Caulerpa taxifolia on mechanisms related to sea urchin egg cleavage. Aquat Toxicol 35:139-155

Pettit GR, Singh SB, Niven ML, Hamel E, Schmidt JM (1987) Isolation, structure, and synthesis of combretastatins A-1 and B-1, potent new inhibitors of microtubule assembly, derived from Combretum caffrum. J Nat Prod 50(1): 119-131

Peyrot V, Barbier P, Sarrazin M, Briand C, Andreu JM (1999) Chirality and spectroscopic changes induced by the recognition of ethyl 5-amino-2-methyl-1,2-dihydro-3-phenylpyrido[3,4-b]pyrazin-7-yl carbamate analogs by tubulin. Photochem Photobiol 70:710-718

Pirollet F, Derancourt J, Haiech J, Job D, Margolis RL (1992a) $\mathrm{Ca}(2+)$-calmodulin regulated effectors of microtubule stability in bovine brain. Biochemistry 31:8849-8855

Pirollet F, Margolis RL, Job D (1992b) Ca(2+)-calmodulin regulated effectors of microtubule stability in neuronal tissues. Biochim Biophys Acta 1160:113-119

Pourroy B, Honore S, Pasquier E, Bourgarel-Rey V, Kruczynski A, Briand C, Braguer D (2006) Antiangiogenic concentrations of vinflunine increase the interphase microtubule dynamics and decrease the motility of endothelial cells. Cancer Res 66:3256-3263

Ravelli RB, Gigant B, Curmi PA, Jourdain I, Lachkar S, Sobel A, Knossow M (2004) Insight into tubulin regulation from a complex with colchicine and a stathmin-like domain. Nature 428:198-202

Risinger A, Mooberry SL (2010) Taccalonolides: novel microtubule stabilizers with clinical potential. Cancer Lett 291:14-19

Rowinsky EK, Wright M, Monsarrat B, Donehower RC (1994) Clinical pharmacology and metabolism of taxol (paclitaxel): update 1993. Ann Oncol 5(Suppl 6):S7-S16

Sharp DJ, Rogers GC, Scholey JM (2000) Microtubule motors in mitosis. Nature 407:41-47

Smith JA, Jordan MA (2010) Determination of drug binding to microtubules in vitro. Methods Cell Biol 95:289299

Stengel C, Newman SP, Leese MP, Potter BV, Reed MJ, Purohit A (2010) Class III beta-tubulin expression and in vitro resistance to microtubule targeting agents. $\mathrm{Br} \mathrm{J}$ Cancer 102:316-324

Tait SW, Green DR (2010) Mitochondria and cell death: outer membrane permeabilization and beyond. Nat Rev Mol Cell Biol 11:621-632

Takanari H, Yosida T, Morita J, Izutsu K, Ito T (1990) Instability of pleomorphic tubulin paracrystals artificially induced by Vinca alkaloids in tissue-cultured cells. Biol Cell 70:83-90

Teicher BA, Doroshow JH (2012) The promise of antibody-drug conjugates. N Engl J Med 367(19):1847-1848

Tsvetkov FO, Kulikova AA, Devred F, Zernii E, Lafitte D, Makarov AA (2011) Thermodynamics of calmodulin and 
tubulin binding to the vinca-alkaloid vinorelbine. Mol Biol (Mosk) 45:697-702

van der Vaart B, Akhmanova A, Straube A (2009) Regulation of microtubule dynamic instability. Biochem Soc Trans 37: 1007-1013
Vertessy BG, Harmat V, Bocskei Z, Naray-Szabo G, Orosz F, Ovadi J (1998) Simultaneous binding of drugs with different chemical structures to $\mathrm{Ca} 2+-$ calmodulin: crystallographic and spectroscopic studies. Biochemistry 37:1530015310 